\title{
WYKORZYSTANIE CIEPLA ODPADOWEGO W PROCESIE PRZYGOTOWANIA SPALIN NA POTRZEBY SEPARACJI METODĄ VPSA
}

\begin{abstract}
$\mathrm{W}$ ostatnich latach są prowadzone intensywne prace związane $\mathrm{z}$ ograniczeniem emisji $\mathrm{CO}_{2}$ do atmosfery $\mathrm{z}$ procesów spalania paliw węglowych w energetyce. W ramach tych prac powstały już nowe technologie oksyspalania, jak również kilka metod separacji $\mathrm{CO}_{2}$ ze spalin. Jedną z nich jest technologia adsorpcyjna VPSA (Vacuum Pressure Swing Adsorption). W technologii VPSA proces adsorpcji i desorpcji jest realizowany przez zmianę ciśnienia. Skuteczność tej metody zależy w dużym stopniu od właściwości sorbentu i jego zdolności sorpcyjnej względem $\mathrm{CO}_{2}$. Parametrami, które wpływają na pojemność sorpcyjną sorbentu, jest temperatura spalin i ich ciśnienie. W przypadku stosowanych sorbentów pojemność sorpcyjna bardzo wzrasta wraz z obniżeniem temperatury spalin i wzrostem ciśnienia. W takim przypadku jest możliwe ograniczenie rozmiarów jednostki adsorpcyjnej, a także kosztów procesu wstępnego sprężania spalin. W pracy przedstawiono propozycję technologii przygotowania spalin kotłowych na potrzeby procesu VPSA, przy założeniu minimalizacji kosztów energetycznych tego procesu i zapotrzebowania na sorbent. W ramach proponowanej technologii zakłada się wykorzystanie ciepła odpadowego ze spalin na potrzeby zasilania chłodziarki absorpcyjnej wytwarzającej wodę lodową. W wyniku przeprowadzonych obliczeń symulacyjnych określono zapotrzebowanie na energię do wstępnego procesu sprężania spalin przed jednostką VPSA oraz minimalne zapotrzebowanie sorbentu do separacji $\mathrm{CO}_{2}$ z przepływającego przez adsorber strumienia spalin.
\end{abstract}

Słowa kluczowe: CCS, chłodziarka adsorpcyjna, redukcja emisji $\mathrm{CO}_{2}$

\section{Wstęp}

Jednym z rozwiązań pozwalających na ograniczenie emisji $\mathrm{CO}_{2}$ do atmosfery lub jej całkowite wyeliminowanie jest zastosowanie $w$ istniejących lub nowo budowanych układach technologii separacji $\mathrm{CO}_{2}$ ze spalin. Obecnie istnieją dwie dojrzałe technologie pozwalające na realizację procesu separacji $\mathrm{CO}_{2} \mathrm{ze}$ spalin: technologia absorpcyjna [2,3] oraz technologia adsorpcyjna [4]. Ich za-

\footnotetext{
${ }^{1}$ Autor do korespondencji/corresponding author: Robert Zarzycki, Politechnika Częstochowska, ul. Brzeźnicka 60A, 42-200 Częstochowa, tel.: (34) 3257334, e-mail: zarzycki@ is.pcz.czest.pl.

${ }^{2}$ Marcin Panowski, Politechnika Częstochowska, e-mail: mpanowski@is.pcz.czest.pl.
} 
stosowanie przyczynia się jednak do obniżenia sprawności wytwarzania energii elektrycznej i ciepła, a tym samym podnosi koszty produkcji tych nośników energii.

W artykule przedstawiono koncepcję układu pozwalającego na ograniczenie negatywnego wpływu zastosowania technologii adsorpcyjnej VPSA przez wykorzystanie ciepła odpadowego ze spalin bloku nadkrytycznego o mocy 900 MWe na potrzeby ich przygotowania do procesu separacji $\mathrm{CO}_{2}$.

\section{Proces separacji $\mathrm{CO}_{2} \mathrm{z}$ wykorzystaniem technologii adsorpcyjnej}

Pomimo intensywnego rozwoju technologii związanych z konstrukcją i budową kotłów sprawność tych urządzeń w zależności od rodzaju spalanego paliwa waha się od 90 do $95 \%$. Największą stratą energii w przypadku kotłów energetycznych jest strata wylotowa. Wiąże się ona $\mathrm{z}$ wysoką temperaturą spalin opuszczających kocioł i zawartą w nich parą wodną. W przypadku rozważanego bloku nadkrytycznego o mocy $900 \mathrm{MW}_{\mathrm{e}}$ opalanego węglem brunatnym projektowana temperatura wylotowa spalin wnosi $170^{\circ} \mathrm{C}$, strumień spalin mokrych to $1090,2 \mathrm{~kg} / \mathrm{s}$ przy strumieniu paliwa $248,35 \mathrm{~kg} / \mathrm{s}$. Zawartość wilgoci w spalinach wynosi ok. $25 \%$ przy zawartości $\mathrm{CO}_{2}$ na poziomie $12 \%$.

Jedną $\mathrm{z}$ technologii separacji $\mathrm{CO}_{2}$ ze spalin jest technologia adsorpcyjna. Polega ona na wykorzystaniu odpowiednich sorbentów stałych, które pozwalają na fizyczne lub chemiczne związanie na ich powierzchni wybranego składnika gazowego. W przypadku sorbentów istotna jest ich wysoka selektywność na separowany składnik (np. $\mathrm{CO}_{2}$ ) i bardzo niska na inne składniki spalin, a także pojemność sorpcyjna, zależna od warunków prowadzenia procesu separacji, a w szczególności temperatury i ciśnienia. W technologii VPSA wykorzystuje się zależność pojemności sorpcyjnej sorbentu od ciśnienia, a zatem realizacja procesu separacji wymaga tutaj wytworzenia pewnego poziomu nadciśnienia spalin przed adsorberem, a następnie dużego podciśnienia w celu realizacji procesu desorpcji.

Przykładową zależność pojemności sorpcyjnej sorbentu względem dwutlenku węgla od ciśnienia (ciśnienia cząstkowego $\mathrm{CO}_{2}$ ) przedstawiają charakterystyki zamieszczone na rys. 1. Analizując przedstawione zależności, można zaobserwować, że wzrost ciśnienia cząstkowego separowanego $\mathrm{CO}_{2}$, a tym samym ciśnienia spalin, powoduje wzrost pojemności sorpcyjnej sorbentu. $Z$ tego też względu, wybierając zakres ciśnień, w którym występuje największy gradient zmienności pojemności sorpcyjnej, można efektywnie i przy możliwie niskich nakładach energetycznych realizować proces separacji $\mathrm{CO}_{2}$ ze spalin. $\mathrm{W}$ przypadku metod adsorpcyjnych istotnym parametrem, oprócz zmian ciśnienia, jest także temperatura gazu, przy czym gradient zmian pojemności sorpcyjnej w funkcji ciśnienia cząstkowego $\mathrm{CO}_{2}$ jest znacznie większy dla niższych temperatur niż dla temperatur wyższych. 


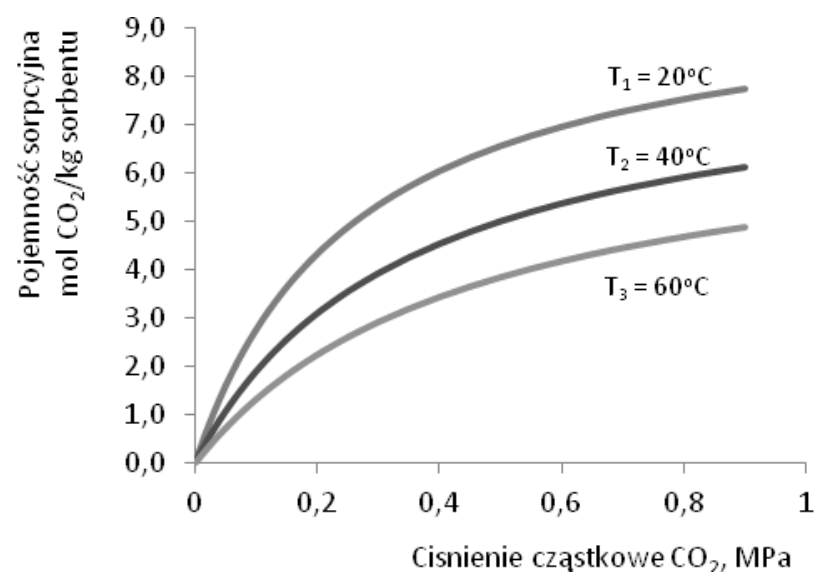

Rys. 1. Izotermy $\mathrm{CO}_{2}$ przykładowego sorbentu

Fig. 1. $\mathrm{CO}_{2}$ isotherms of exemplary sorbent

Można zatem stwierdzić, że obniżenie temperatury spalin przed procesem VPSA może się przyczynić do znaczącego ograniczenia zapotrzebowania na sorbent oraz do wyraźnego zmniejszenia kosztów energetycznych procesu. Jednym z problemów technicznych w przypadku realizacji procesu separacji $\mathrm{CO}_{2}$ ze spalin są koszty sprężania wstępnego spalin przed jednostką VPSA oraz gabaryty tej jednostki ze względu na duży strumień objętości spalin o wysokiej temperaturze. Chcąc ograniczyć koszty energetyczne separacji $\mathrm{CO}_{2}$ ze spalin oraz koszty inwestycyjne instalacji VPSA, koniecznie należy ochłodzić spaliny do możliwie niskiej temperatury.

\section{Wykorzystanie ciepła odpadowego w procesie ochładzania spalin przed jednostką VPSA}

Mając na uwadze sformułowany wniosek dotyczący możliwie niskiej temperatury spalin przed procesem VPSA, konieczne jest ich ochłodzenie. Można rozważać odbiór ciepła niskotemperaturowego od spalin na potrzeby bloku parowego, np. podgrzew regeneracyjny wody lub wykorzystać to ciepło np. w obiegu ORC zabudowanym w sąsiedztwie bloku parowego bądź utracić je bezpowrotnie w chłodni kominowej. Realizując zaproponowane sposoby ochłodzenia spalin, należy jednak szacować, że przy zastosowaniu najsprawniejszych wymienników ciepła możliwe jest ich ochłodzenie do temperatury rzędu $50-60^{\circ} \mathrm{C}$, co wynika z dostępności we wspomnianych propozycjach odpowiedniego czynnika chłodzącego. W przypadku chłodni kominowej w okresie letnim powracający czynnik do chłodzenia spalin może posiadać temperaturę ponad $30^{\circ} \mathrm{C}$, co stanowi wartość zbliżoną do temperatury kondensatu za skraplaczem obiegu parowego. Jedynie zastosowanie urządzeń chłodniczych pozwala na uzy- 
skanie znacząco niższych temperatur czynnika chłodzącego. Do ich pracy konieczne jest jednak dostarczenie energii, co może podwyższyć koszty energetyczne tego procesu. Jednym z rozwiązań tego problemu może być zainstalowanie chłodziarki absorpcyjnej bromowo-litowej, która pozwala na przygotowanie czynnika chłodzącego (wody lodowej) o temperaturze ok. $4-5^{\circ} \mathrm{C}$ (rys. 2.).

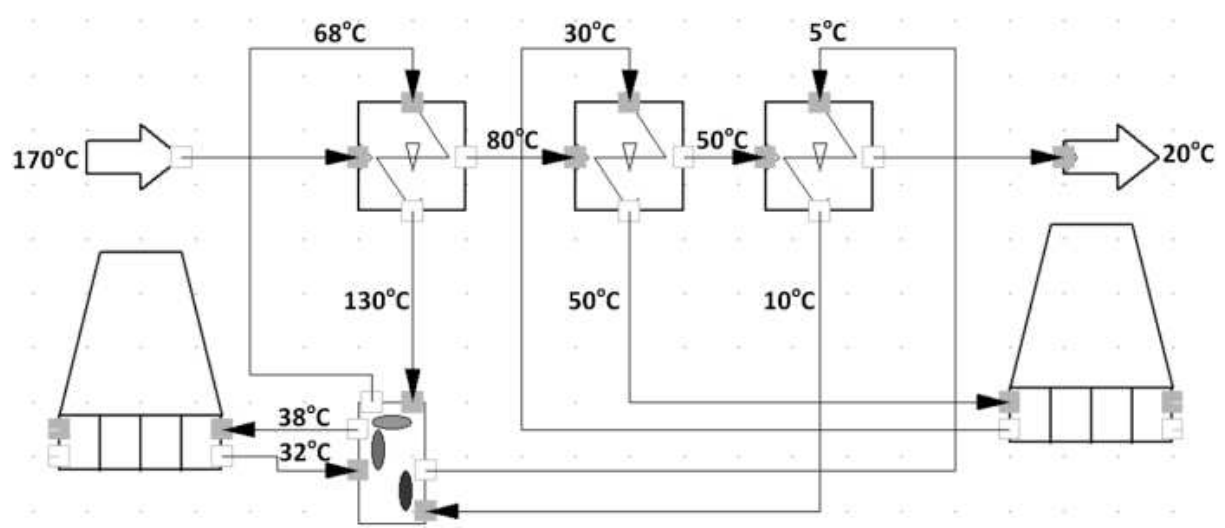

Rys. 2. Schemat procesu odzysku ciepła ze spalin na potrzeby przygotowania wody lodowej

Fig. 2. The scheme of a process of heat recuperation from exhaust gas for cold water preparation

Chłodziarka wymaga do pracy gorącej wody o temperaturze maksymalnej $130^{\circ} \mathrm{C}$ (chłodziarka dwustopniowa) lub $95^{\circ} \mathrm{C}$ (chłodziarka jednostopniowa), dopuszcza się jednak zasilanie chłodziarki wodą o niższej temperaturze [1]. Uzyskanie wody o założonej wcześniej temperaturze wymaga zabudowania wymiennika ciepła w ciągu spalinowym. Dzięki temu możliwe jest także wstępne ochłodzenie spalin do temperatury ok. $80^{\circ} \mathrm{C}$ w przypadku chłodziarki dwustopniowej, z której wypływa woda do pierwszej sekcji wymiennika ciepła o temperaturze ok. $68^{\circ} \mathrm{C}$. Dalsze ochłodzenie spalin może być realizowane za pośrednictwem wody z chłodni kominowej, która przepływa przez drugą sekcję wymiennika ciepła i pozwala na ochłodzenie spalin do temperatury ok. $45-50^{\circ} \mathrm{C}$, przy silnej kondensacji zawartej w spalinach pary wodnej. W tym przypadku wspomniana porcja ciepła zawarta w spalinach jest tracona w chłodni kominowej. Zastosowanie tego rozwiązania pozwala na znaczące zmniejszenie mocy chłodniczej chłodziarki absorpcyjnej, a tym samym kosztów inwestycyjnych takiego układu. Dalsze obniżanie temperatury spalin następuje w trzeciej sekcji wymiennika ciepła, do której jest wprowadzana woda lodowa. W tym przypadku uzyskuje się dalsze obniżanie zawartości wilgotności w spalinach, a dzięki niskiej temperaturze wody lodowej możliwe jest ochłodzenie spalin do ok. $20^{\circ} \mathrm{C}$. 


\section{Proces separacji $\mathrm{CO}_{2}$ metodą VPSA}

Proces separacji dwutlenku węgla ze spalin metodą VPSA przedstawiono na rys. 3. Składa się on z etapu wstępnego $\left(\mathrm{CMP}_{\mathrm{s}}\right)$ sprężania spalin przygotowanych zgodnie $\mathrm{z}$ rys. 2 . od ciśnienia ok. $0,1 \mathrm{MPa}$ do ciśnienia ok. 0,2 MPa przed pierwszą sekcją DR-VPSA 1 . W celu uzyskania produktu separacji o wysokiej koncentracji $\mathrm{CO}_{2}$ proponuje się zastosowanie metody DR-VPSA. Metoda Dual Reflux VPSA pozwala na dwustopniową realizację procesu separacji $\mathrm{CO}_{2}$ ze spalin. W pierwszym etapie separowanie $\mathrm{CO}_{2}$ ze spalin prowadzi do uzyskania produktu zawierającego ok. $60 \% \mathrm{CO}_{2}$. W drugim etapie DR-VPSA 2 jest poddawany separacji $\mathrm{CO}_{2} \mathrm{z}$ produktu otrzymanego po pierwszym etapie. $\mathrm{W}$ tym przypadku ciśnienie cząstkowe $\mathrm{CO}_{2}$ jest odpowiednio wyższe niż w przypadku spalin, co wymaga już nieco mniejszej ilości sorbentu do separacji zawartego tam $\mathrm{CO}_{2}$. Ciśnienie wyseparowanego $\mathrm{CO}_{2}$ po procesie DR-VPSA 2 wynosi 0,005 $\mathrm{MPa}$. W tym przypadku konieczne jest jego sprężenie $\left(\mathrm{CMP}_{\mathrm{ps} 2}\right)$ do ciśnienia $0,1 \mathrm{MPa}$, pozwalającego na skierowanie do układu sprężania na potrzeby transportu $\mathrm{w}$ fazie nadkrytycznej. $\mathrm{W}$ celu ograniczenia energochłonności proponuje się ochładzanie przepływającego przez układ separacji gazu do temperatury $20^{\circ} \mathrm{C}$ każdorazowo przed procesem jego sprężania.

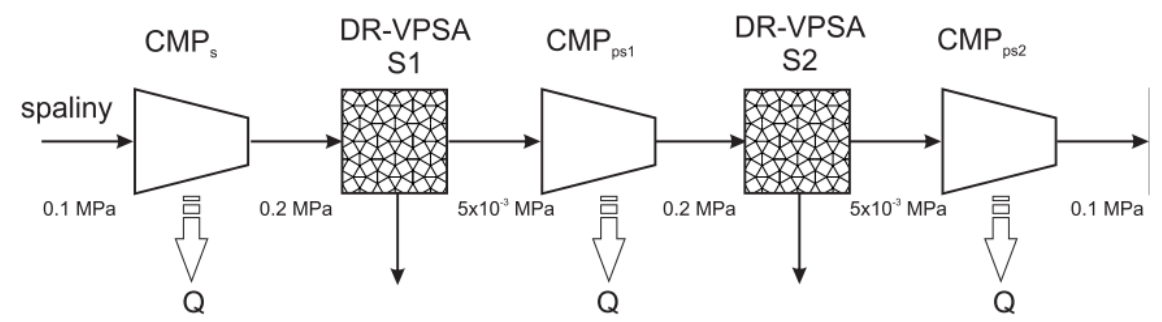

Rys. 3. Schemat procesu separacji VPSA dwutlenku węgla ze spalin

Fig. 3. The scheme of VPSA separation ofcarbon dioxide from exhaust gas

Wpływ obniżenia temperatury spalin oraz produktu po procesie VPSA został przedstawiony na rys. 4-6. Wpływ temperatury spalin przed jednostką VPSA przedstawiono na rys. 4. Linią z otwartymi kwadratami zilustrowano zapotrzebowanie na strumień sorbentu do separacji w pierwszym etapie DR-VPSA $_{1}$, natomiast linią z otwartymi kołami - do separacji DR-VPSA $A_{2}$. Różnice w zapotrzebowaniu na sorbent pomiędzy DR-VPSA ${ }_{1}$ i DR-VPSA Drnikają $_{2}$ z różnego ciśnienia cząstkowego $\mathrm{CO}_{2} \mathrm{w}$ spalinach (sekcja 1.) oraz w produkcie sekcji 2., który zawiera ok. $60 \% \mathrm{CO}_{2}$. Widoczny jest jednak wpływ temperatury na wymagany do separacji strumień sorbentu. Dla założonej temperatury spalin $20^{\circ} \mathrm{C}$ zapotrzebowanie na sorbent wynosi odpowiednio ok. $7500 \mathrm{~kg} / \mathrm{s}$ i ok. $2500 \mathrm{~kg} / \mathrm{s}$, co daje sumaryczne zapotrzebowanie na poziomie $10000 \mathrm{~kg} / \mathrm{s}$. Wzrost temperatury gazu do $30^{\circ} \mathrm{C}$ powoduje wzrost zapotrzebowania na stru- 
mień sorbentu do poziomu $12500 \mathrm{~kg} / \mathrm{s}$, a w przypadku temperatury spalin $40^{\circ} \mathrm{C}$ - do ponad $15000 \mathrm{~kg} / \mathrm{s}$. Przy dalszym wzroście temperatury widoczny jest jeszcze bardziej wzrost zapotrzebowania na strumień sorbentu do separacji $\mathrm{CO}_{2}$. $\mathrm{W}$ przypadku temperatury ok. $53^{\circ} \mathrm{C}$ zapotrzebowanie na strumień sorbentu jest blisko dwukrotnie wyższe niż przy $20^{\circ} \mathrm{C}$. Przedstawione wartości zapotrzebowania na sorbent $\mathrm{w}$ procesie separacji $\mathrm{CO}_{2}$ przekładają się bezpośrednio na gabaryty jednostki VPSA oraz koszt jej wypełniania sorbentem. Na podstawie przeprowadzonych wstępnych analiz stwierdzono, że gabaryty jednostki adsorpcyjnej i wymagany dla niej teren stanowią istotny problem przy jej zabudowie w sąsiedztwie bloku parowego.

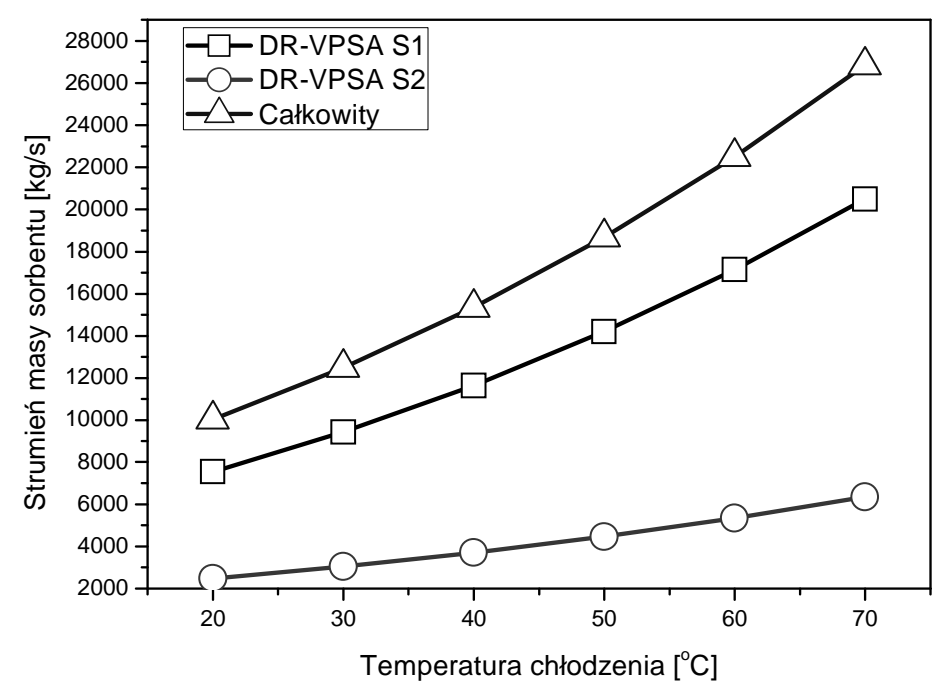

Rys. 4. Zapotrzebowanie na sorbent $\mathrm{w}$ funkcji temperatury spalin

Fig. 4. Sorbent demand as a function of exhaust gas temperature

Istotnym problemem zastosowania technologii separacji $\mathrm{CO}_{2}$ ze spalin i przygotowania go na potrzeby transportu i składowania są koszty energetyczne tego procesu. Wiążą się one głównie z zapotrzebowaniem na moc do napędu wentylatorów spalin i sprężarek $\mathrm{CO}_{2}$, co przedstawiono na rys. 5 .

Jak widać, w przypadku temperatury gazu $20^{\circ} \mathrm{C}$ zapotrzebowanie na moc do procesu VPSA wynosi ok. $175 \mathrm{MW}$, natomiast wzrost temperatury do 40 i $60^{\circ} \mathrm{C}$ wymaga odpowiednio mocy ok. 190 i $205 \mathrm{MW}$. Zapotrzebowanie to oczywiście obciąża potrzeby własne bloku z DR-VPSA i podnosi koszty produkcji energii elektrycznej. Zastosowanie chłodzenia spalin może się zatem przyczynić do wzrostu mocy o ok. $30 \mathrm{MW}$, co stanowi ponad 3\% mocy bloku.

Jednym z ważnych wskaźników pozwalających porównywać różne technologie separacji $\mathrm{CO}_{2}$ jest jednostkowe zużycie ciepła (rys. 6.). W przypadku temperatury $20^{\circ} \mathrm{C}$ jednostkowe zużycie ciepła do separacji $\mathrm{CO}_{2}$ wynosi ok. 2,22 
$\mathrm{MJ} / \mathrm{kg} \mathrm{CO}$. Wzrost temperatury do $40 \mathrm{i} 60^{\circ} \mathrm{C}$ powoduje odpowiednio wzrost zapotrzebowania na ciepło w ilości 2,39 i $2,57 \mathrm{MJ} / \mathrm{kg} \mathrm{CO}_{2}$. W przypadku stosowania metod absorpcyjnych opartych na roztworach amin jednostkowe zapotrzebowanie na ciepło kształtuje się na poziomie 3,0-3,5 MJ/kg CO 2 .

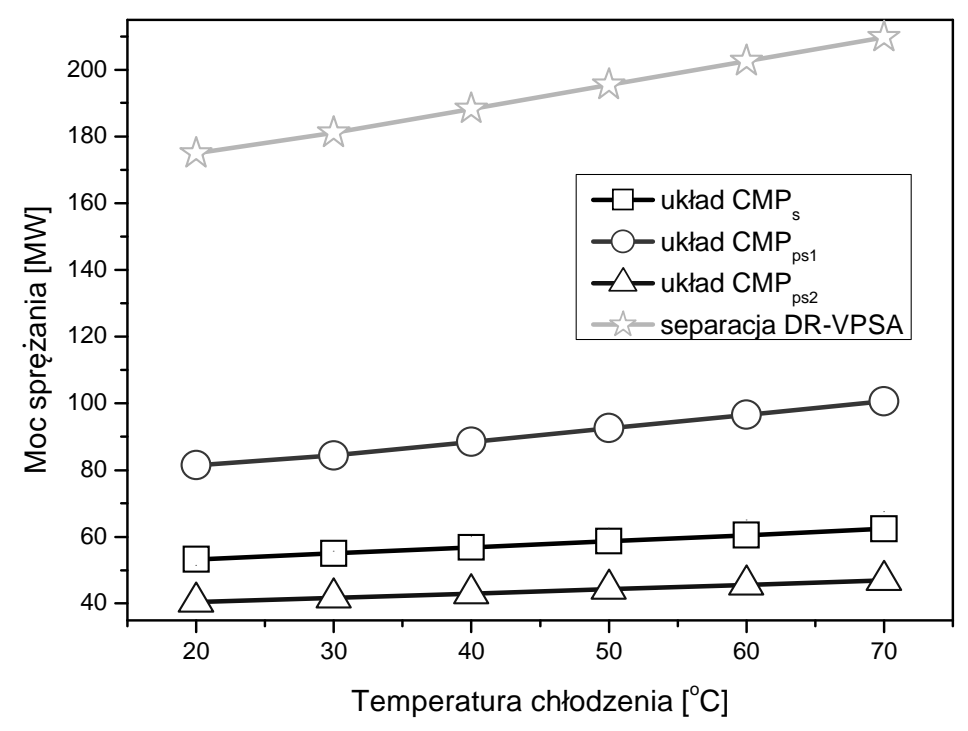

Rys. 5. Zapotrzebowanie na moc do procesu sprężania

Fig. 5. Power demand for compression process

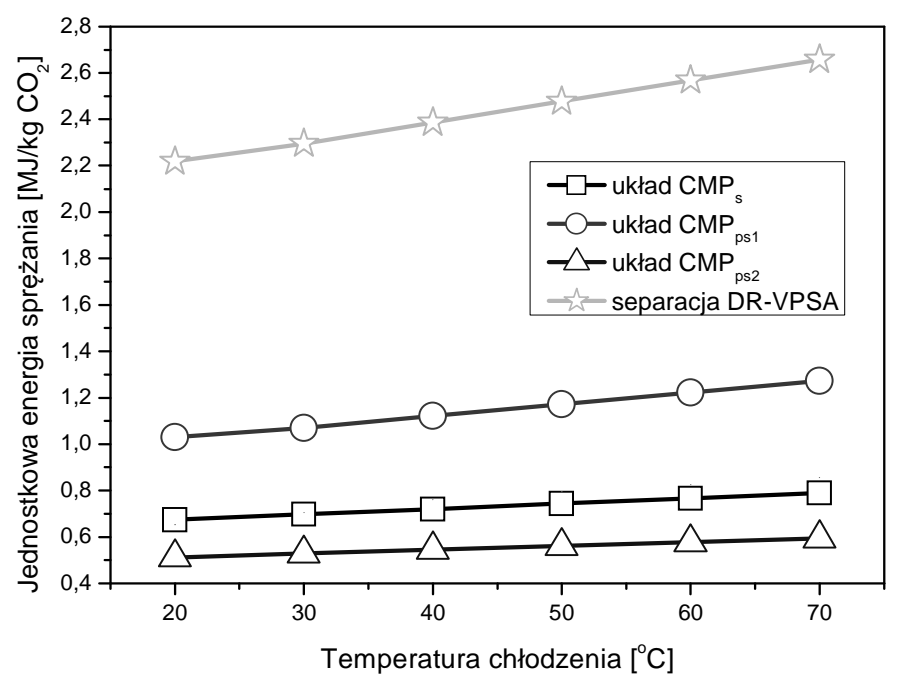

Rys. 6. Jednostkowy koszt energetyczny procesu sprężania

Fig. 6. Unit energetic cost of compression process 


\section{Podsumowanie}

Zaproponowana $\mathrm{w}$ pracy technologia wykorzystania ciepła odpadowego spalin na potrzeby ich ochładzania przed procesem VPSA pozwala przede wszystkim na ograniczenie zapotrzebowania na strumień sorbentu, co wpływa bezpośrednio na rozmiary oraz koszty tej instalacji. Dodatkowo ochłodzenie spalin pozwala ograniczyć energochłonność procesu sprężania spalin i $\mathrm{CO}_{2}$, co ma bezpośredni wpływ na podwyższenie sprawności wytwarzania energii elektrycznej. Technologia adsorpcyjna DR-VPSA pozwala osiągnąć wyraźnie niższe jednostkowe zapotrzebowanie na ciepło w porównaniu z technologiami absorpcyjnymi opartymi na roztworach amin.

\section{Podziękowanie}

Przedstawione w artykule wyniki zostały uzyskane w badaniach współfinansowanych przez Narodowe Centrum Badań i Rozwoju w ramach umowy SP/E/1/67484/10 - Strategiczny Program Badawczy - Zaawansowane technologie pozyskiwania energii: Opracowanie technologii dla wysokosprawnych ,zero-emisyjnych" bloków węglowych zintegrowanych z wychwytem $\mathrm{CO}_{2}$ ze spalin.

\section{Literatura}

[1] http://www.shuangliang.com/eng/product.asp?ID=24 (dostęp: 11 lipca 2014 r.).

[2] Majchrzak-Kucęba I.: Testing and evaluation of novel $\mathrm{CO}_{2}$ adsorption, Environmental Engineering, Taylor \& Francis Group, London 2013.

[3] Wawrzyńczak D., Majchrzak-Kucęba I., Nowak W.: Badania separacji $\mathrm{CO}_{2}$ na wybranych sorbentach metodą adsorpcji zmiennociśnieniowej PSA, Budownictwo i Inżynieria Środowiska, Wydawn. Politechniki Białostockiej, 1 (2010), 85-89.

[4] Więcław-Solny L., Tatarczuk A., Krótki A., Stec M.: Postęp prac w badaniach technologicznych aminowego usuwania $\mathrm{CO}_{2}$ ze spalin, Polityka Energetyczna, t. 16, z. 4. Wydawn. Instytutu GSMiE PAN, Kraków 2013, s. 229-241.

\section{WASTE HEAT UTILISATION FOR FLUE GAS PRETREATMENT DUE TO CARBON DIOXIDE SEPARATION BY VPSA METHOD}

\section{S u m m a r y}

One of research carried out intensively nowadays is the one on reduction of $\mathrm{CO}_{2}$ emission to atmosphere from fossil fuel combustion in energy sector. The new technologies like oxycombustion or technologies of separation from the flue gas were developed as their result. One of separation technologies considered is VPSA (Vacuum Pressure Swing Adsorption) adsorption on solid sorbents, which is done owing to different pressures on both, adsorption and desorption side of the unit. The efficiency of this method depends on solid sorbent properties and its sorption capacity in respect of separated gas components. The thermodynamic parameters of the separation process that influence sorption capacity are temperature and pressure. This is because the sorption capacity strongly increases with lowering temperature and increasing pressure of the flue gas. Therefore, in such conditions, sorbent demand for separation decreases that makes separation unit 
to be much smaller, and moreover, it makes flue gas compression process less energy consuming. The paper presents the concept of technology of flue gas pretreatment that may minimise energy cost of separation and sorbent demand for $\mathrm{CO}_{2}$ separation. Proposed technology assumes utilisation of waste heat from flue gas for feeding the absorption cooler that produces cold water for flue gas cooling. This allows not only flue gas cooling but in the same time for moisture removal, which also has positive impact on separation process. As a result of calculation performed, the energy demand for flue gas compression as well as sorbent amount were assessed and showed advantages of proposed technology.

Keywords: CCS, absorption cooler, $\mathrm{CO}_{2}$ emission reduction

DOI: $10.7862 / \mathrm{rm} .2015 .28$

Otrzymano/received: $14.09 .2014 \mathrm{r}$.

Zaakceptowano/accepted: 20.03.2015 r. 